\title{
0 LÚDICO NO DESENVOLVIMENTO DAS POTENCIALIDADES CRIATIVAS MUSICAIS NA PRIMEIRA INFÂNCIA
}

\section{THE LUDIC IN THE DEVELOPMENT OF MUSICAL CREATIVE POTENTIALITIES IN EARLY CHILDHOOD}

Cláudia Jaqueline de Souza Siufi*

Universidade de São Paulo - claudiasiufi@gmail.com Silvia Maria Pires Cabrera Berg**

Universidade de São Paulo - silviaberg@usp.br

Fecha de recibo: 17 - $11-2019$

Fecha de aprobación: $22-11-2019$

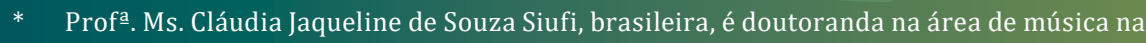
Escola de Comunicações e Artes da Universidade de São Paulo (ECA/USP). No Mestrado defendeu dissertação sobre os processos de aprendizado musical na primeira infância. Possui graduação em Pedagogia com especialização em Educação Musical. Trabalha como professora de música para Educação Infantil e Ensino Fundamental há 25 anos. Universidade de São Paulo - claudiasiufi@gmail.com

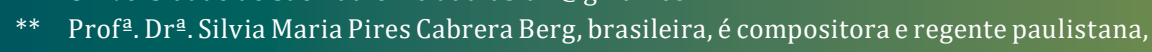
bacharel em composição pela ECA-USP (1982), bolsista CNPQ na Universidade de Oslo ( 1984) e Cand. Mag pela Universidade de Copenhague (1992). Atualmente, é docente do Departamento de Música da FFLCRP-USP, coordenadora do Laboratório de Pesquisas Inter e Transdisciplinares em Música (LAPECIPEM) e de seu grupo performático Oficina Experimental, primeira coordenadora do Arquivo Edmar Ferretti, atualmente pertencente ao Centro de Memória das Artes, coordenadora do Intercâmbio Acadêmico Internacional com Bornekorakademiet (Dinamarca) e membro do Núcleo de Pesquisa em Ciências da Performance em Música da FFCLRP - USP NAP-CIPEM - do Departamento de Música da FFCLRP-USP. silviaberg@usp.br. 


\section{Resumo}

Este artigo apresenta uma visão do desenvolvimento criativo musical na primeira infância (de dois a cinco anos) que parte da exploração sonora para a construção de um fazer musical próprio das crianças, tendo o jogo e a atividade lúdica como base estrutural para o aprendizado. Compreendemos que o desenvolvimento das potencialidades criativas utilizando sons e ruídos como matéria de exploração permite a ampliação de ideias e conceitos musicais proporcionando a formação de sujeitos ativos, perceptivos, sensíveis e perspicazes para uma relação diferenciada e aberta com o mundo que lhes cerca. A partir das propostas de François Delalande e suas interfaces com teóricos como Gilles Deleuze e Johan Huizinga, propomos uma abordagem destinada a uma faixa etária que, embora prevista nas propostas teóricas de Delalande, não foi suficientemente abordada no ensino para essa determinada faixa etária. Ao final, apresentamos um relato de uma experiência realizada em escola regular com alunos de Educação Infantil.

Palavras-Chave: Criatividade, ludicidade, infância, educação musical.

\section{Resumen}

Este artículo presenta una visión del desarrollo musical creativo en la primera infancia (de dos a cinco años) partiendo de la exploración sonora a la construcción de la propia creación musical de los niños, teniendo la actividad lúdica como una base estructural para el aprendizaje. Entendemos que el desarrollo del potencial creativo utilizando el sonido y el ruido como material de exploración permite la expansión de ideas y conceptos musicales, proporcionando la formación de temas activos, perceptivos, sensibles y perspicaces para una relación diferenciada y abierta con el mundo que los rodea. Basado en las propuestas de François Delalande y sus interfaces con teóricos como Gilles Deleuze y Johan Huizinga. Se propone un enfoque dirigido a un grupo de edad que, aunque previsto en las propuestas teóricas de Delalande, este grupo de edad en particular no se aborda lo suficiente en la enseñanza. Al final, se presenta un informe de experiencia realizado en la escuela regular con estudiantes de jardín de infantes

Palabras clave: Creatividad, ludicidad, infancia, educación musical.

\section{Abstract:}

This paper presents a vision of the creative musical development in the early childhood (from two to five years old ) departing from the sound exploration to the construction of a children's own musical making, having the playful activity as a structural basis for learning. We understand that the development of creative potential using the sound and the noise as a material of exploration allows the expansion of ideas and musical concepts, providing the formation of active, perceptive, sensitive and insightful subjects for a differentiated and open relationship with the world around the children. Based on the proposals of François Delalande and their interfaces with theorists such as Gilles Deleuze and Johan Huizinga, we propose an approach aimed at an age group which, although foreseen in Delalande's theoretical proposals, this particular age group is not sufficiently addressed in teaching. At the end, we present an experience report conducted in regular school with kindergarten students.

Key words: Creativity, ludicity, childhood, musical education. 
Em sua origem etimológica as palavras criança e criatividade derivam do mesmo radical latino creare que, conceitualmente, traduz o sentido de criar. A criança traz dentro de sua essência a busca do novo e da descoberta, por conseguinte, o ato inventivo - intimamente conectado à inquiribilidade e ludicidade ${ }^{1}$ nos primeiros anos da existência- é um dos grandes atributos do ser humano que pode e deve ser desenvolvido desde a primeira infância através de estímulos e desafios. Ativa e investigativa a criança testa e elabora hipóteses diante de tudo o que lhe é exposto no seu dia a dia e, trabalhando de forma criativa, desenvolve habilidades a partir da curiosidade, da exploração e da descoberta, incluindo nesta cinesia tudo aquilo que se relaciona ao sonoro. Prevista teoricamente por Delalande (1995, 2013), no entanto, há poucos registros de que a práxis com essa faixa etária tenha sido suficientemente comprovada, especialmente em escolas de ensino regular.

Em uma breve atenção auditiva ao que ocorre ao redor é notório perceber que o ambiente em que se vive é ruidoso e musical ao mesmo tempo e, apoiando-se neste princípio de que a audição é construída tanto com sons quanto com ruídos², portanto os processos criativos podem ser incentivados e desenvolvidos desde a infância através de trabalhos sonoros baseados em uma escuta sensível e na exploração sonora. Esta escuta sensível e atenta permite perceber e selecionar os sons que mais afetam e que trazem significado; a partir disso, um infinito caminho para a exploração, percepção, produção, organização, criação e composição sonora pode se abrir.

\section{0 jogo lúdico como ferramenta para 0 desenvolvimento criativo musical}

Quando nos referimos à infância muitas vezes nos remetemos à ideia da brincadeira $\mathrm{e}$ do lúdico. Com um olhar transformador, que é próprio de quem vive no jogo, a criança é movida por um pensamento mágico e imaginativo em tudo o que realiza. Assim sendo, toda a atividade lúdica pode compreender um espaço para a criação, interação e desenvolvimento social e cultural, proporcionando ao sujeito uma sensação de liberdade para um mergulho em si mesmo e entrega à fruição. Huizinga (2014) cita que "os jogos infantis possuem a qualidade lúdica em sua própria essência, e, na forma mais pura desta qualidade." (Huizinga, 2014: 21).

Huizinga (2014) defende que o lúdico faz parte do humano onde o que mais importa é a ação em si, o movimento vivido, o pensamento, o sentimento, a integração:

O jogo é uma função da vida, mas não é passível de definição em termos lógicos, biológicos ou estéticos. 0 conceito de jogo deve permanecer distinto de todas as outras formas de

1 Estes conceitos são amplamente discutidos na dissertação de mestrado "A ludicidade ea inquiribilidade no processo da educação musical na primeira infância” (Siufi, 2018:18-22,51-53).

2 Utilizamos aqui o conceito que define o som como resultado de uma vibração regular e ruído como resultado de uma vibração irregular (ROSS, 2009). 
pensamento através das quais exprimimos a estrutura da vida espiritual e social. [...] Ornamenta a vida, ampliando-a e nessa medida torna-se uma necessidade tanto para o indivíduo, como função vital, quanto para a sociedade, devido ao sentido que encerra, à sua significação, a seu valor expressivo, a suas associações espirituais e sociais, em resumo, como função cultural. Dá satisfação a todo o tipo de ideais comunitários. Nesta medida, situa-se numa esfera superior aos processos estritamente biológicos de alimentação, reprodução e autoconservação (Huizinga, 2014: 10-12).

Deleuze (2011) afirma que o jogo ideal é aquele que acontece enquanto pensamento em movimento "pois só o pensamento pode afirmar todo o acaso, fazer do acaso um objeto de afirmação. Se tentarmos jogar este jogo fora do pensamento, nada acontece e, se tentarmos produzir um resultado diferente da obra de arte, nada se produz." (Deleuze, 2011: 63)

Deleuze (2011) e Huizinga (2014) complementam-se quanto à relação entre o jogo e a arte. Deleuze (2011) pressupõe que a arte leva ao estado do jogo e o jogo como modo de pensamento, além disso Huizinga (2014) apresenta a ideia de que o jogo, assim como a arte, não faz parte das utilidades da vida prática. Nesta relação entre arte e jogo encontramos na música muitos elementos que os aproximam. Assim como o jogo, a música é relativa ao ser humano e ambos não se direcionam à praticidade e à funcionalidade em sua essência. Somos seres de sensações e é através da música, da escuta, que se faz possível o resgate do sentido do jogo como ritual. A arte se apresenta aqui como a qualidade do jogo que dispara sensações. Huizinga (2014) e Deleuze (2011) pensam a música como o jogo ideal, mergulhado em outros tempos, não ao tempo Cronos —o qual conhecemos —, porém ao tempo Aion, em que o jogo se dá sem pensar na finalidade, mas nele por si só. Segundo Deleuze " Cronos é preenchido pelos estados de coisas e os movimentos de objetos que mede" (Deleuze, 2011: 67). Ao contrário, Aion é o tempo que "não tem necessidade de ser infinito, mas somente “infinitamente subdivisível'” (Deleuze, 2011: 64). 0 tempo Aion pode estender o tempo cronológico, pois " cada acontecimento sobre o Aion é menor que a menor subdivisão no Cronos; mas é também maior que o maior divisor de Cronos, isto é, o ciclo inteiro" (Deleuze, 2011: 66). Quando o tempo Aion invade o tempo Cronos abre-se espaço para a criatividade, uma vez que Aion indica movimento, um tempo e espaço interno que se exterioriza. 0 jogo e o lúdico e, consequentemente, a arte e a música advêm deste espaço, onde o jogo é o lugar em que as coisas se entrelaçam: o jogo da arte - o jogo das crianças - o jogo ideal.

\section{O som como matéria prima para o desenvolvimento das potencialidades criativas}

Desde que nasce a criança se relaciona com o mundo através dos sentidos. Explora cores, cheiros, formas, sabores e interage de forma curiosa e destemida diante do novo que se apresenta. Da mesma forma a criança toma uma postura exploratória com o 
ambiente sonoro que a cerca e, sendo a música então entendida como um processo contínuo de construção que envolve perceber, sentir, experimentar, imitar, criar e refletir, consideramos que a interação da criança com a linguagem musical deva ocorrer desde cedo a partir da exploração, da pesquisa e da criação, por meio da interação entre o sujeito e o sonoro.

Sendo o corpo o primeiro instrumento do homem (Mauss, 1934) ${ }^{3}$ e o meio de relação da criança com o universo, é a partir da exploração dos sons corporais que a ideia de música se inicia. 0 corpo pode produzir uma vasta variedade de sons quando percutirmos as mãos ou os pés sobre diferentes partes do corpo e de superfícies ou quando trabalhamos com o ar e a boca de diversas maneiras. Esta exploração sonorocorporal pode ser incentivada desde os primeiros anos de idade, pois é através do corpo que a criança se comunica. À medida que cresce novos desafios podem ser apresentados como a exploração de corpos sonoros diversificados numa investigação atenta à diversidade de sonoridade que um mesmo material pode apresentar se manuseado de formas diferentes. Este processo permite que a criança brinque e ao mesmo tempo perceba a importância da diversificação do gesto e da ação sobre o objeto para a descoberta de novos sons, desenvolvendo seu potencial criativo para que, em outro momento, possa trabalhar e criar a partir de timbres e sons melódicos em instrumentos musicais.

Ao longo da infância e como consequência de sua relação com o ambiente e com o sonoro, as crianças criam ideias de música e constroem o seu fazer musical. Consideramos este fazer musical como um conjunto de elementos e ações junto ao sonoro que são espontâneos para a criança e estão na constituição do desenvolvimento humano. Delalande (1995) afirma que a música imita o real. Segundo o autor, no interior da música pode-se descobrir certo número de esquemas e de organizações da matéria sonora que possuem em comum um movimento encontrado no que já foi vivido e experienciado pelo sujeito. É importante destacar que a criança lida com o sonoro de uma forma própria e, aos poucos, vai transformando seu fazer musical de acordo com sua percepção de música. Para a criança não existe uma só música, existem várias músicas, várias ideias de música.

Para a criança pequena "tocar" é produzir "gesto". Ela explora a sonoridade dos objetos e instrumentos musicais e mais tarde começa a perceber e tomar consciência da sua própria musicalidade. Enquanto pequenas, as ideias de música das crianças ainda são um conceito muito aberto. Aos poucos estas ideias vão adquirindo contornos por influências externas de acordo com aquilo que vê, ouve, observa ou mesmo através da intervenção dos adultos. Todas as fases do desenvolvimento humano estão intrinsecamente ligadas quando se faz música e, assim sendo, deve-se respeitar desde cedo o pensamento musical da criança aberto à percepção do sonoro.

3 Em As técnicas do corpo (1934) o antropólogo francês Marcel Mauss apresenta a ideia de que o corpo é o primeiro instrumento, o primeiro objeto técnico que o homem aprende a utilizar, opondo as técnicas do corpo às técnicas dos instrumentos. As técnicas do corpo se referem aos modos pelos quais o homem sabe servir-se de seu corpo de maneira tradicional, variando de uma sociedade a outra. 
De acordo com o psicólogo e biólogo Piaget (1978), enquanto se desenvolve, a criança passa por estágios de aprendizagem que caracterizam a expressão da capacidade de apreensão do conhecimento. Para Piaget (1978) são quatro os períodos experienciados necessariamente em sequência, onde cada fase alicerça a fase seguinte de maneira que as aquisições ocorridas em um estágio constituem pré-requisito para o estágio seguinte. Delalande (1995) relaciona estes estágios ao aprendizado musical. Segundo o autor, o primeiro estágio do desenvolvimento da criança se denomina estágio sensóriomotor, em que a experimentação e a exploração ganham grande força. Posteriormente, a criança apresenta uma fase onde a representação corporal e o imaginário estão muito presentes, essa fase se denomina estágio simbólico. Na medida em que a criança cresce e amadurece aparecem as combinações intelectuais agora já reguladas por um código, fase que Delalande (1995) chama "jogo de regras". Contudo, contrapondo o que defende Piaget (1978), Delalande (1995) acredita que estes estágios não são estagnados tampouco têm começo e fim, pois sempre que se depara com um novo material sonoro, a criança percorre os mesmos caminhos circulando entre idas e vindas, envolvida pela exploração e pelo imaginário, construindo o seu próprio fazer musical num caminho criativo que guarda similaridades com experiências anteriores.

Delalande (2013) classifica a sequência do jogo de construção musical em quatro momentos que se sucedem:

Exploração: Quando colocada diante de um novo material, a criança inicialmente o manipula involuntariamente, examinando seus elementos e suas propriedades sonoras.

Descobrimento: Circunstância em que aparece, de modo repentino, uma configuração que capta a atenção da criança, ou porque evoca algo já conhecido ou porque possui uma regularidade particular.

Projeto: Neste momento, a criança se sente desafiada à tarefa de complementação ao resultante da exploração e elabora, por conseguinte, um projeto de execução com o material sonoro com o qual interagiu.

Realização: A partir desse estágio, a execução é fiel ao percurso de exploração e descoberta seguindo o projeto idealizado, inclusive integrando novas descobertas e esta regra de conduta determina a regularidade da construção musical. (Delalande 2013: 124)

Sob esta ótica, as práticas pedagógicas musicais infantis devem tomar a ludicidade como ponto de partida, estimulando o imaginário, desenvolvendo a escuta criativa e a capacidade de invenção sonora sem exigir que a criança possua conhecimentos musicais prévios. A produção musical deve ser de ordem qualitativa e não quantitativa, onde a busca da sonoridade deve vir primeiro.

O fazer musical se torna jogo ao tratar de sons e silêncios, formas e timbres. Ao adentrar neste jogo por meio da ludicidade e da inquiribilidade, a criança brinca com o sonoro experimentando a sensação de liberdade: joga, discute, cria e encontra soluções para os problemas que surgem durante o aprendizado. Neste processo o cérebro trabalha em e com muitas sinapses, além disso a criança passa a perceber o 
quanto a combinação de sons e a subsequente organização formam o que chamamos música. A sua música, a música da criança.

É importante ressaltar que o jogo da música é diferente do jogo elaborado para ensinar determinado conceito na música. Ele se faz por si mesmo quando deixa de ser funcional para ser expressivo, possibilitando a ludicidade individual e com o outro. É por meio da vivência do jogo musical que a interação entre saberes acontece de forma integrada, onde a criança é protagonista de seu próprio aprendizado, promovendo o desenvolvimento de habilidades e potencialidades criativas: "através da brincadeira se exploram fontes sonoras, se imita o real, se organizam os sons. A criação nasce do jogo" (Delalande, 1995: 61). 0 mais importante é preservar o jogo e o caráter lúdico no desenvolvimento e aprendizado musical.

A partir da ludicidade a criança aprende conceitos, desenvolve a criatividade, descobre a si próprio e percebe-se como integrante do meio social. Em consequência, o lúdico passa a ser o meio para toda a relação da criança com o outro, com o ambiente, com os objetos e com o sonoro. Através da fruição e do prazer que abrange as brincadeiras, a criança se envolve no jogo sonoro, sente e aprende, vive e internaliza, cria e transforma, construindo seu fazer musical e apropriando-se deste conhecimento:

A brincadeira pode ser compartilhada e comunicada com outros pela adoção de um código. É no meio da brincadeira que os participantes mutuamente criam uma "diferença que faz a diferença". [...] brincar é autopoiético (autogerador) e autotélico (automotivador) [...] brincar não é o nome de um comportamento empírico, mas sim o nome de uma certa estruturação de ações. (Bo Kampmann, 2005: 250)

Ao relacionarmos o conceito de poiesis ${ }^{4}$ como processo criativo envolvendo a ação e o conhecimento encontramos traços comuns na ideia de aprendizado e desenvolvimento criativo musical proposto por Delalande. 0 autor defende que a criação musical inicia a partir da busca sonora através da exploração de fontes sonoras. Ao aguçar a sensibilidade diante de materiais e objetos sonoros oportunizamos três grandes tipos de condutas, que Delalande (2013) classifica assim: 1) explorar, 2) expressar, 3) construir. Estas condutas representam o caminho em direção à invenção e criação musical.

Entre as atividades lúdicas, expressadas pela criação e automotivação, ressaltamos as cirandas de roda como importante prática no desenvolvimento musical

4 Comentamos aqui o conceito etimológico de poiesis por entender a fundamental importância deste relacionado à práxis musical na infância. Conforme Souza: "Expressão originária do verbo poiéo (fabricar, executar, confeccionar), poíesis traduz-se por fabricação, confecção, preparação, produção. Todavia, um "produzir que dá forma, um fabricar que engendra, uma criação que organiza, ordena e instaura uma realidade nova, um ser". Criação não no sentido hebraico de fazer algo a partir do nada, mas no sentido grego de gerar e produzir dando forma a partir de uma matéria preexistente e ao mesmo tempo prenhe de potencialidades. [...] Poíesis, na verdade, designa o ato ou o processo de criação, como se diz que a criação, o ser criado por meio desse processo ou ato, o seu resultado, é o poíema. Poíesis é, enfim, a noção que designa, genericamente, a aptidão para a criação, para a inauguração de sentidos que são e estão no criado como conteúdo (sentido) e expressão (realização), ao mesmo tempo" (Souza, 2007: 86-87). 
compreendendo a oralidade, o canto em uníssono, a percepção espacial, o movimento corporal e o senso rítmico. As cirandas também proporcionam o desenvolvimento da coordenação espaço-temporal e de habilidades de socialização e cooperação através da interação com o coletivo:

Na música, a criança encontra elementos que lhe permite descobrir e reencontrar seu corpo físico; ela se reconhece como ser que pode perceber, ouvir, criar, movimentar, interagir diretamente num determinado espaço; adquire habilidades e comportamentos criativos e críticos, que irão contribuir para o seu desenvolvimento integral. Nesse sentido, a utilização de um repertório musical que faça uso das Cirandas, pode contribuir sobremaneira para o desenvolvimento social, afetivo e físico da criança. (Loureiro, 2011:7)

As brincadeiras rítmicas por meio de jogos corporais, jogos de mãos ou jogos de copos permitem o desenvolvimento da atenção, percepção e coordenação motora formando a base necessária para um estudo instrumental mais adiante. Além disso, a experimentação sonora partindo de diferentes fontes oportuniza o desenvolvimento das capacidades criativas, ampliando o repertório de sons e possibilitando construções sonoras que podem incentivar futuras composições musicais.

\section{Relato de experiência}

Considerando a educação musical um processo contínuo de construção que implica perceber, sentir, experimentar, imitar, criar e refletir, apresentamos um estudo de caso relatando a experiência realizada em aulas de música de Educação Infantil em escola regular da rede privada, envolvendo alunos entre dois e cinco anos de idade, suas interrelações com o sonoro e o desenvolvimento da criatividade envolvendo sons. As aulas se caracterizaram por encontros semanais de 30 minutos, no caso de alunos entre dois e três anos, e encontros de 40 minutos com alunos entre quatro e cinco anos.

Descrevemos aqui um projeto desenvolvido ao longo de um semestre, intitulado "Um mundo de sensações sonoras", cujo principal objetivo era permitir às crianças um contato livre com corpos sonoros diversos, partindo da proposta de investigação com materiais diversificados como papéis, objetos plásticos e de metal, para estimular a inquiribilidade e a expressividade no fazer musical infantil. Nosso intuito era oportunizar às crianças momentos para sentir e apreciar o movimento do som e dos ruídos, de forma que a curiosidade auditiva fosse a principal guia da exploração. Aos alunos mais velhos além da exploração, tínhamos como meta desafiá-los a realizar pequenas organizações e produções sonoras.

Observando-se texturas, tamanhos e outras características que pudessem proporcionar diferenças sonoras, selecionamos previamente os materiais que seriam disponibilizados aos alunos: papéis de diferentes tipos (corrugado, celofane, seda, craft e outros que pudessem produzir sons diferentes ao serem manuseados); objetos plásticos com formas e tamanhos diversificados como baldes, bacias, potes, canos, 
galões, além de plástico bolha e chapas de Raio X; além de objetos de metal como panelas, frigideiras, latas, travessas, colheres e outros materiais metálicos.

Cada material foi trabalhado durante quatro encontros, aproximadamente, sendo a primeira aula dedicada à livre exploração e manuseio dos objetos, sem intervenções quaisquer por parte do professor. Os alunos eram recebidos já com o ambiente preparado, com os materiais dispostos pela sala e eram orientados primeiramente a observar visualmente o material para depois explorarem em todas as suas possibilidades: amassar, raspar, sacudir, rasgar, bater, esfregar, entre outras ações; dando-se expressiva atenção aos sons produzidos nas diferentes formas de manuseio.

A partir do segundo encontro os alunos eram convidados a apresentarem aos colegas os sons que haviam descoberto na exploração inicial e, posteriormente, eram desafiados a criar pequenas construções sonoras, trabalhando com timbres e outros parâmetros do som, como intensidade e/ou duração. Os encontros finais eram momentos de aplicação das descobertas através de sonorização de histórias elaboradas pelos próprios alunos, instrumentação de músicas, reprodução de sons da natureza ou apresentação de pequenas construções sonoras.

Durante a realização do projeto foi possível observar que os alunos entre dois e três anos permaneceram na fase exploratória e investigativa. Ainda não eram capazes de compor alguma construção sonora de forma a mesclar timbres, porém percebiam diferenças sonoras entre os materiais manipulados e as apresentavam quando requisitados. Participaram com entusiasmo e interesse das atividades propostas que envolviam o acompanhamento musical utilizando os sons descobertos e, em algumas vezes, relacionavam os sons com outros conhecidos: como o som do sapo ao raspar o papel corrugado ou o som da chuva ao sacudir e amassar o papel celofane.

Com o período simbólico bastante presente, os alunos de quatro e cinco anos preferiam representar instrumentos como bateria, guitarra ou até mesmo violino com os objetos que dispunham. Também faziam analogias com outros sons e utilizavam deste pensamento para instrumentar histórias próprias ou já conhecidas.

Entre quatro e cinco anos as crianças já começam a perceber melhor a organização sonora, portanto, alguns alunos já compunham pequenas construções sonoras (estruturação de ações) com os materiais, observando diferenças de timbre. Delalande (1995) afirma que as sequências sonoras que as crianças de menos de seis anos produzem, ainda estão muito marcadas pela exploração das fontes ou pelo desejo de simbolizar diretamente uma cena, o que pode ser comprovado ao longo da realização deste projeto.

Através das atividades propostas proporcionamos um contato diferente com o universo sonoro e, ao possibilitar às crianças liberdade de interação com os objetos, a inquiribilidade se tornou guia do processo oportunizando aos alunos o protagonismo da aprendizagem. Ao experimentarem diferentes formas de manuseio e interação com os objetos, novos sons foram descobertos e, ligados a outros, se transformaram em pequenas construções musicais. 
Reconhecemos a partir da execução deste projeto que a relação com a música se expande à medida que se tem a oportunidade de agir sobre ela. As crianças mudaram sua relação com os sons, se tornando mais atentas às possibilidades e começando a interagir com todo e qualquer objeto que pudessem produzir som: criavam ritmos, constatavam diferenças sonoras e orgulhosamente apontavam para suas descobertas e produções.

O desenvolvimento da criatividade a partir da exploração e investigação sonora traz um enorme ganho não só na área artística, mas abre caminho para outras habilidades desenvolvendo a autoconfiança, melhorando a autoestima e ampliando a percepção de mundo que a criança traz consigo. É importante ressaltar que a comunidade escolar também teve a oportunidade de ampliar seus conceitos musicais, abrindo espaço para os ruídos e respeitando as manifestações sonoras produzidas pelas crianças, que são fontes inesgotáveis de criatividade.

Além de todo o trabalho envolvendo exploração e construção sonora, nossas aulas de música também compreendem atividades lúdicas musicais em que são desenvolvidas habilidades como expressão corporal, canto, apreciação musical, noções de ritmo, andamento musical e parâmetros como intensidade e percepções de timbre. Descrevemos aqui algumas atividades em que a ludicidade e a música se entrelaçam.

Toda a aula de música começa com um convite musical: o violão é o instrumento que introduz nosso encontro, buscando as crianças em sala de aula. Caminhamos pela escola, desde a sala de aula até a sala de música cantando acompanhados pelo violão, enchendo os corredores de música. Não há quem nos escute e que não responda com um sorriso, uma cantarolada, uma saudação. A música se apresenta como uma linguagem que afeta a todos aqueles que com ela se deparam.

Entre os dois e três anos de idade, as crianças apresentam ainda uma postura muito individualista. A ideia central está no "Eu", a relação com os outros, com o ambiente, com os sons e a música através do "meu corpo". Diante deste cenário, toda a interação com o sonoro a princípio se dá unilateralmente, ampliando-se à medida que a criança se desenvolve.

Toda a investigação envolve interesse e foco, e mesmo com pouca idade, a criança descobre formas de variação de intensidade, de gesto e de movimento que proporcionam diferentes resultados sonoros. A pesquisa e a busca acompanham a criança todo o tempo, todos os dias, pois tudo pode ser pesquisado e explorado, tudo lhe interessa.

Sendo o corpo o principal meio de comunicação e interação nesta faixa etária, buscase em um primeiro momento um trabalho de percepção espacial e corporal a partir de brincadeiras musicais com muito movimento. Para estas atividades usamos tanto músicas do cancioneiro infantil como música erudita, folclórica e popular urbana.

Algumas brincadeiras musicais se destacam e estão entre as preferidas das crianças desta faixa etária, como o "Camaleão" na qual letra e melodia, que convidam ao movimento, permitem que as crianças andem e dancem pelo ambiente sem chocar-se 
com objetos ou outros colegas, percebendo o espaço que lhes insere e a brincadeira do "Gigantão" que tem o intuito de perceber corporalmente a intensidade sonora.

De mesma forma, porém já com a intenção de trabalhar a percepção de ritmo, além da noção espacial, utilizamos o Movimento VI da peça Le Carnaval des Animaux de Camille Saint-Säens, intitulada "Kangourous". Nesta atividade as crianças precisam ouvir e movimentar-se pelo espaço de acordo com o ritmo que o trecho da música propõe. No caso específico desta música, o som do piano parece muitas vezes saltitar, hesitar ou até mesmo parar, momentos em que as crianças são desafiadas a demonstrar através de seus movimentos esta percepção sonora.

A investigação sonora também parte do corpo e, consequentemente, trabalhamos a sensibilidade táctil e exploração sonora através da experimentação do plástico bolha. Nesta atividade a criança parte da curiosidade e certo receio diante do material desconhecido para a exploração e pesquisa, percebendo a ação de seu corpo sob o objeto e interagindo com o sonoro a partir de sua experimentação.

A percepção auditiva também é uma habilidade desenvolvida em nossas aulas. Partimos da identificação de sons de animais e de fenômenos da natureza através de um jogo de cartelas em que as crianças relacionam o som que ouvem às imagens que lhe são apresentadas. 0 principal objetivo desta atividade é fazer a criança atentarse aos sons identificando-os, aprimorando assim sua acuidade auditiva para que posteriormente possa perceber diferenças de timbre em sons de objetos sonoros ou instrumentos musicais.

Iniciando pela identificação sonora dos animais, as atividades nas aulas de músicas costumam envolver sons, movimento corporal, canto e apreciação musical. Como exemplo, descrevemos aqui as atividades envolvendo a identificação sonora do rugido do leão:

A princípio espalhamos cartelas com diversas imagens de animais e pedimos que as crianças fiquem atentas ao som que irão ouvir. Depois pedimos que identifiquem e nomeiem o animal ao qual ouviram o som, selecionando a cartela com a imagem referida. Ao identificarem o leão, repetimos a escuta, agora olhando para a imagem e tentando reproduzir com a voz o rugido do animal. Feito isso, os alunos são convidados a movimentarem-se pela sala ao som de "Introduction et marche royale du lion" tema original de Camille Saint-Saëns, da obra Le Carnaval des Animaux, onde os dois pianos trinam e arpejam fazendo referência à marcha do soberbo animal, imitando seus rugidos. Brincamos com o corpo, com os sons, cantamos músicas tradicionais da infância e, no final, concluímos com a apreciação musical ouvindo "Leãozinho" de Caetano Veloso. Assim, procuramos trabalhar de forma que a criança possa interagir com os sons e com a música, seja ela instrumental ou em forma de canção, seja de origem popular ou erudita, possibilitando diferentes percepções, ampliando repertório sonoro e musical sempre envolvendo a ludicidade.

A identificação sonora também passa pelos sons de fenômenos da natureza, sendo a chuva, o vento e o trovão sons que trabalhamos sob vários aspectos. Além da audição 
procuramos desenvolver junto às crianças possibilidades de reprodução sonora, seja utilizando sons corporais, de objetos sonoros ou instrumentos musicais. No intuito de se chegar à reprodução que mais pudesse se aproximar ao som original. "A chuva" foi o resultado de um trabalho de escuta e seleção de sons construído junto com as crianças com diálogos e muita troca de ideias.

Entre os dois e três anos a criança já consegue se comunicar usando um maior repertório de palavras, período em que a linguagem oral está em pleno desenvolvimento e a canção entra como um importante apoio. Neste sentido, trabalhamos com músicas do cancioneiro infantil bem como com canções da MPB ou acompanhados do canto das professoras e de violão, ou ainda com gravações em arranjos cuidadosamente selecionados. Acreditamos que as canções tradicionais da infância devam conter arranjos cuidadosos que sejam capazes de atrair a atenção das crianças aos instrumentos.

O canto em uníssono é uma habilidade que se desenvolve ao longo do tempo, pois a organização coletiva acontece gradativamente. Utilizamo-nos de cantigas e cirandas de roda para o trabalho com o canto, bem como para o desenvolvimento da percepção espacial e corporal. Nestas atividades o movimento lateral e o ritmo conjunto são enfatizados, permitindo que a criança se utilize da linguagem corporal, musical e cênica e possibilitando aprendizagens afetivas, cognitivas e sociais de forma que possa compreender-se no jogo coletivo. Entre as cirandas de roda preferidas estão aquelas que contam histórias ou que compreendem bastante movimentação corporal: "Periquito Maracanã" em que os movimentos corporais acompanham a letra da música tornando-se desafiadores ou "0 galo e a galinha" que pode ser enriquecida com adereços para os personagens principais, são apreciadas e sempre requisitadas.

Em nossas aulas utilizamos instrumentos de percussão para o acompanhamento de canções e brincadeiras musicais fazendo questão de que as crianças se familiarizem com o som, o nome e o manuseio destes. As brincadeiras com as músicas "O tomate e o caqui" (Grupo Trii) e "Pom pom pom” (tradicional da infância), entre outras, permitem que desenvolvamos a atenção rítmica ao acompanhá-las utilizando os coquinhos.

Entre os quatro e cinco anos de idade, o eixo central da aprendizagem se amplia e, além da inter-relação do indivíduo com os outros, com os sons e com a música, pretende-se a aplicação dos conhecimentos até aqui então adquiridos nas construções e organizações sonoras. Nesta faixa etária a linguagem oral já se encontra bem desenvolvida, o repertório de canções envolve letras maiores e mais complexas; brincadeiras com parlendas, lenga-lalengas, trava-línguas, versos e poesias se intensificam.

Neste período o simbólico prevalece e as canções que envolvem objetos cênicos ou as dramatizações envolvendo cantigas de roda são muito apreciadas. Há maior atenção ao movimento e ao jogo coletivo, enfatizando o simbólico das histórias que perpassam as cantigas de roda. "A Linda Rosa Juvenil" e "A Carrocinha Pegou" são muito apreciadas pelas crianças que as solicitam com frequência em nossas aulas. Também a sonorização de histórias é uma atividade bastante presente, sejam histórias 
já conhecidas ou mesmo histórias criadas pelos próprios alunos. Para tanto, todo o material sonoro é discutido e escolhido em conjunto, bem como em quais partes da história o som será produzido. Os instrumentistas também escolhem qual som será de sua responsabilidade e, por fim, a sonorização se concretiza.

A atenção sonora e acuidade auditiva também são desenvolvidas em atividades lúdicas. Um jogo desafiador é o das "Caixinhas Sonoras" que consiste em pares de caixinhas de fósforos com materiais que produzem som ao serem chacoalhadas. Cabe às crianças, sem abrir as caixas, encontrar seu "par", ou seja, outra caixinha que possua o mesmo som. Nesta atividade há minúcias de timbre entre um som e outro o que torna o desafio mais intenso cujo principal objetivo está no desenvolvimento da escuta ativa.

Outra atividade relacionada à escuta se refere à observação de paisagens sonoras. Realizamos esta atividade em passeios pela escola ou através de vídeos que representem diferentes paisagens sonoras. De outra forma, propomos a escuta de uma paisagem sonora em que as crianças devem relacioná-la a uma imagem apresentada ou reproduzi-la com o corpo por meio de sons corporais, com a voz ou com objetos sonoros.

Com a habilidade de escuta aprimorada, podemos iniciar um trabalho mais específico com instrumentos de percussão disponíveis na sala de música como cocos, chocalhos, tambores, triângulos, clavas, reco-recos, entre outros. Perto dos cinco anos a criança já começa a construir organizações sonoras demonstrando suas percepções rítmicas e de timbre. Costumam montar "baterias" misturando tambores de tamanhos diferentes a outros objetos que possam produzir sons diferenciados ou trabalhando em conjunto com outros colegas e outros sons, demonstrando muito prazer em apresentar suas descobertas sonoras. Em outros momentos oferecemos a todos um mesmo instrumento propondo-lhes um improviso musical e, neste caso, há crianças que demonstram maior capacidade de criação do que outras, pois algumas variam somente intensidade enquanto outras já envolvem duração criando sequências rítmicas.

A percepção rítmica se inicia em uma conversa sobre o ritmo da natureza, o ritmo das marés e o ritmo do nosso corpo. Ouvimos as batidas de nosso coração e percebemos que esta constância também acontece na música. Propomos atividades e jogos rítmicos utilizando clavas ou cocos para acompanhamento. Com as noções rítmicas já mais desenvolvidas, trabalhamos então o acompanhamento de pequenas canções e parlendas através de jogos de copos ou jogos de mãos. Ao longo das atividades é possível perceber quais crianças já apresentam maior domínio rítmico e quais outras precisam de apoio e intervenção por parte da professora. Por fim, como projeto desafiador, propomos a instrumentação de músicas em que a atenção auditiva e a percepção rítmica são colocadas em prática.

No intuito de estimular o contato com diferentes fontes sonoras, instituímos o Dia do Instrumento Musical. Neste dia, que acontece uma vez por mês, a criança pode trazer de casa um instrumento musical de "verdade" ou de "brinquedo", ou mesmo um instrumento construído com material reciclado. Ela apresenta seu instrumento aos 
colegas, toca, improvisa e depois, compartilha com o grupo que pode experimentálo também. No final, cantamos músicas de nosso repertório comum das aulas, acompanhados com estes instrumentos.

A criança vivencia a música desde que nasce, relaciona-se com sons, experimenta, testa e cria e é na escola onde todo este conhecimento prévio deve ser aproveitado, potencializado e ampliado, cultivando o interesse pelo sonoro e o gosto pelas diferentes formas de música. Toda a atividade realizada em nossas aulas de música requer preparo, pesquisa e atenção ao desenvolvimento infantil, respeitando sempre o aluno como indivíduo único que está em processo de aprendizagem. Acreditamos que é através da ludicidade de forma séria e precisa que as crianças se envolvem com a música, aprendendo conceitos, desenvolvendo habilidades e, principalmente, ampliando sua capacidade criadora.

\section{Conclusão}

Ao compreender que a inter-relação da criança com a música se dá por meio da ludicidade, se faz importante uma reflexão da prática nas aulas de iniciação musical para a primeira infância. É fundamental entender que a criança possui várias ideias de música e outros modos de tratar do tempo, por conseguinte, devem-se proporcionar diferentes formas de fazer música junto às crianças.

É por meio da liberdade de ação que o lúdico propõe à criança uma experiência plena para o desenvolvimento da criatividade e a construção de seu próprio fazer musical, desde a exploração sonora partindo da própria voz até chegar à utilização de instrumentos. Em seu percurso, há um contínuo movimento circular em que a criança passa por diversos estágios de desenvolvimento musical; contudo sem abandoná-los ao longo da aprendizagem e criação. Sempre há um trabalho sensório-motor ligado ao gesto instrumental e uma dimensão simbólica que confere um caráter expressivo à música.

Neste sentido, é preciso perceber que apreender é muito mais profundo do que aprender. 0 processo de "aprender" vem do externo para o interno e, em contrapartida, "apreender" abarca um movimento muito maior que vem do interior para o exterior. Num contexto em que haja uma dinâmica entre música, criação e ação é fundamental que a criança seja estimulada a apreender, trabalhando com os sons e objetos sonoros de forma lúdica envolvendo possibilidades de exploração, organização e criação.

Diante disso, acreditamos que educar musicalmente as crianças não seja tirá-las de um "nada musical" em que se supunha que estivessem, para levá-las a determinado nível de competência; pelo contrário, desenvolver uma atividade lúdica que já existe dentro delas e que é, em última análise, a mesma fonte do jogo e da performance musical. Compreender que a criança possui capacidades e potencialidades de exploração, ação e criação a partir do sonoro é fundamental para o trabalho com música na primeira fase da infância; no entanto, sabe-se que, apesar de pressupostos teóricos, há poucos registros de que a práxis tenha sido comprovada em escolas de ensino regular. Desta 
forma, ao relatar as experiências ocorridas nas aulas de Educação Infantil com alunos de dois a cinco anos, pode-se confirmar as propostas previstas por Delalande.

O desenvolvimento das potencialidades criativas tem na ludicidade, através do jogo ideal, o movimento para contribuir na formação de indivíduos sensíveis, perceptivos, atentos e perspicazes, capazes de se relacionar com o mundo de forma diferenciada e aberta.

\section{Referências}

Assis, Orly Z. Mantovanni de. (1994). “O jogo simbólico na teoria de Piaget”. Proposições, 5(1)[13], 99-108. Disponível em:

http://periodicos.sbu.unicamp.br/ojs/index.php/proposic/article/ viewFile/8644339/11758(Acesso em: 27 novembro,2019).

Bo Kampmann, Walther. (2005). Brincando e jogando: Reflexões e Classificações. En: Teoria Digital. Festival Internacional de Linguagem Eletrônica (pp. 245-255). Barreto, Ricardo; Perissin, Paula (Org.) São Paulo: Imprensa Oficial do Estado de São Paulo. En: < https://file.org.br/wp-content/uploads/2013/11/FILE_10Anos_ps2.pdf> (novembro, 2019).

Brito, Teca Alencar. (2003). Música na Educação Infantil: propostas para formação integral da criança, 2a ed. São Paulo: Peirópolis.

Brito, Teca Alencar de. (2013). De Roda em Roda: brincando e cantando o Brasil. São Paulo: Editora Fundação Peirópolis.

Brougère, Gilles.(1998). Jogo e educação. Porto Alegre: Artes Médicas.

Delalande, François. (1995). La musica es un juego de niños. Buenos Aires: Ricordi Americana.

Delalande, François. (2013). Las Conductas Musicales. Santander: Editorial de la Universidad de Cantabria.

Deleuze, Gilles. (2011). Lógica do Sentido, Coleção Estudos 35. São Paulo: Perspectiva.

Howard, Walter.(1984).A música e a criança, São Paulo:Summus.

Huizinga, Johan. (2014). Homo Luden: O jogo como elemento da Cultura, Coleção Estudos 4. São Paulo: Perspectiva. 
Loureiro, Maristela; Lima, Sonia Albano de. (2012) "As cirandas brasileiras e sua inserção no ensino fundamental e nos cursos de formação de docentes." DAPesquisa, Florianópolis, v. 7, n. 9, p. 393-410 ISSN 1808-3129. En: <http://www.revistas.udesc. br/index.php/dapesquisa/article/view/13971/9054>. (abril, 2020). doi:https://doi.or $\mathrm{g} / 10.5965 / 1808312907092012393$.

Mauss, Marcel. (2005). “As técnicas do corpo". In: Sociologia e Antropologia. São Paulo: CosacNaify

Piaget, J. (1978). A formação do símbolo na criança. Rio de Janeiro: Zahar.

Ross, Alex. (2009). O Resto é Ruído. Escutando o século XX. São Paulo: Companhia das Letras

Saint-Saëns, Camille (1886). Le Carnaval des Animaux. París: Duran.

Souza, Jovelina Maria Ramos de. (2007) “As origens da noção de poíesis". Revista Hypnos. ano 13 / no 19 - $2^{\circ}$ sem. - São Paulo / p. 85-96. En: <http://www.hypnos.org.br/ revista/index.php/hypnos/article/view/450/510> (março, 2020)

Siufi, Cláudia Jaqueline de Souza. (2018). A ludicidade e a inquiribilidade no processo da educação musical na primeira infância. (Dissertação de Mestrado em Processos de Criação Musical, Escola de Comunicações e Artes, Universidade de São Paulo, São Paulo). 